\title{
Some Clinical and Biochemical Effects Associated With Acute Malathion-Induced Immunotoxicity in Minia City, Egypt
}

\author{
Hefnawy A.A ${ }^{1}$, Hend M.Moness², Amr R.Zaki ${ }^{3}$, Manal Ewais Hassan and Naglaa Adly A ${ }^{4}$ \\ ${ }^{1}$ Department of Forensic Medicine and Clinical Toxicology, Faculty of medicine, Minia University, Egypt. \\ ${ }^{2}$ Department of clinical pathology, Faculty of Medicine, Minia University, Egypt. \\ ${ }^{3}$ Department of Forensic Medicine and Clinical Toxicology-Faculty of medicine, Beni -Suef university, Egypt. \\ ${ }^{4}$ Department of Medical Biochemistry and Molecular Biology. Faculty of medicine, Beni -Suef University, Egypt.
}

\begin{abstract}
Pesticides have been implicated in increasing the prevalence of diseases associated with alterations of the immune response. The purpose of this review was to demonstrate some clinical effects and to investigate some biochemical changes that occur with acute malathion pesticide intoxication regarding immune system. During a period of six months that started from 1st of November 2014 till $30^{\text {th }}$ of April2015, 43 subjects were chosen to be involved in this study. They were divided into 2 groups: group A (control): 10 apparently healthy subjects and group B: consists of 33 patients acutely intoxicated by malathion. Pseudocholine estrase enzyme level, interleukin 2 (IL-2), and cluster of differentiation cells (CD4, CD8 and CD19) were investigated for all subjects. The results of the current study revealed significant increase in male intoxicated cases andingestion was the most common route of intoxication. The mean ages of patients was $30.1 \pm 8.5$ years old. Suicidal intent was the common mode of toxicity.The mean of delay interval between intoxication and hospital admission was $8.3 \pm 5.8$ hours. Significant statistical differences in all vital signs, local and some systemic manifestation of the patient. Pseudocholine esterase level was reduced in all cases. Significant decrease in CD4, CD8 and CD19 cell count, while significant increase in IL-2 levels in group 2 patients as compared to control subjects. Significant positive correlation was evident between IL-2 and CD4 count, while significant negative correlation between IL-2 and CD19 count appeared. Insignificant correlations between pseudocholine esterase level and (CD 19, CD8 \& CD4) and between IL-2 and (CD8 \& Pseudocholine esterase level) were noticed. Critical cases represent $27.3 \%$ of patients.Hospital stay duration mean was $8.6 \pm 4.8$ days. The study concluded that acute malathion toxicity can carry the risk of immunotoxicity. There is demand to continue to improve immunotoxicological studies. A concerted effort is required to organize and standardize a study protocol.

Keywords

immunotoxicological, malathione, interleukin 2 (IL-2), cluster of differentiation(CD4, CD8, CD19)
\end{abstract}

\section{Introduction}

P esticides are substances used to kill, repel, or control certain forms of plant or animal life that are considered to be pests. They include for instance, insecticides, herbicides and fungicides. It is estimated that approximately 7000 metric ton (Mt) of herbicides, $8000 \mathrm{Mt}$ of insecticides and $9000 \mathrm{Mt}$ of fungicides are used worldwide every year (Corsini et al., 2013).

Exposure to xenobiotics has the capability of producing any combination of the following recognized adverse outcomes: 1) focused or more extensive immunosuppression, 2) increased propensity for allergic disease, including atopy, food allergies and asthma, 3) hypersensitivity reactions directed at the chemical itself, 4) increased risk of autoimmune disease and 5) dysfunctional inflammatory responses of innate immune cells, producing tissue or organ damage or dysfunction (IPCS, 2012).

The immune system may be a target of several pesticides. (Corsini et al., 2008). Hoppin et al. (2007) and Slager et al. (2010), showed that specific pesticides, including diazinon, chlorpyrifos, dichlorvos, malathion, carbaryl, permethrin, may contribute to elevated rhinitis episodes in farmers. Several studies observed increased infections in human (Sunyer et al., 2010), in occupationally exposed workers, that may be explained by pesticides- induced immunosuppression.

Epidemiological studies raise the possibility that exposures to some pesticides may be involved in 
the pathogenesis of autoimmune diseases, such as rheumatoid arthritis especially in females (Corsini et al., 2013).

The potential of pesticides inducedcarcinogenicity in human is still a matter of debate. Cancer is a multifactorial disease with contributions from genetic, environmental, and life style factors (McDuffie, 2005). Hemopoietic cancers have been associated with pesticides, and cancers of the prostate, pancreas, liver, and other body systems (Jaga and Dharmani, 2005; Orsi et al., 2009; Persson et al., 2012).

Most of evidences of immunotoxic effects werederived from experimental studies. Also, the available data regarding the current evidence of pesticides-induced immunotoxicity in human are incomplete (the majority of the data are relative to old pesticides and only few immune parameters have been investigated) and the results are contradictory or difficult to interpret. In addition, most human epidemiological studies on pesticide-induced immunotoxicity were for chronic or subchronic toxicity.So, this study was carried out to demonstrate some clinical effects and to investigate some biochemicalchanges in the immune system after acute malathion intoxication.

Our clinical study depends on Corsini et al., (2008) who reported that the first phase of immunotoxicity studies should include the determination of CD3, CD4, CD8 (CD4/ CD8 ratio), CD19 and CD16/56 positive cells. The results obtained from this simple test panel are sufficient to display the balance between lymphocyte subpopulations and highlight possible alterations.

\section{Subjects and Methods Subjects}

Our study involved 43 subjects of both sexes.

\section{Clinical protocol}

This study was a cross sectional descriptive study that was conducted prospectively in the period from 1st November 2014 till 30 ${ }^{\text {th }}$ April2015 inPoison Control Center (P.C.C) of Minia University Hospital.The subjects were divided into 2 groups:

Group A: 10 apparently healthy adults with no systemic diseases.

GroupB: 33 patients from the patients admitted at P.C.C of Minia University Hospital, with history of acute malathion organophosphorus insecticide intoxication (suicidal intention and accidental exposure). Both group A and B were matched in age.

The subjects were diagnosed as malathion intoxication by history, presence of specificmalathion residue, clinical manifestations and assay of pseudocholine esterase enzyme level. The cases received antidotal therapy atropine sulphate and oximes (toxogonin which is obidoxime chloride and is a product of Merck-Serono Company)

This clinical study included demographic data collected from the history (sex and age distribution, mode of toxicity, route of intoxication\&delay time of presentation), clinical manifestations (vital signs, local and systemic manifestations), laboratory investigations (pseudocholine esterase enzyme levelenzyme linked immunoassay (ELISA) kits, IL-2 by (ELISA), CD4, CD8, CD19 by flowcytometry), grading of cases (critical and non-critical)antidotetreatment (atropine dose, oximes dose)duration of hospital stayandmortality rate and cause. Critical case was definedaccording to the severity of clinical manifestations (presence of marked muscle weakness, chest wheezes \& crepitation, cyanosis) and the laboratory investigations (decrease of pseudocholine esterase enzyme level below $1000 \mathrm{IU} / \mathrm{ml}$ ). These data were tabulated and analyzed.

\section{Inclusion and Exclusion criteria}

Only patients acutely intoxicated with malathion were involved in this study as it is the most common organophosphorus insecticide used in Minia governorate. Subjects within age group 18-45 years were involved in our research. All subjects with a history of systemic diseases, or concomitant use of any medications were excluded from this study. Any patient with previous treatment trial with atropine or oximes were also excluded.

\section{Human rights}

All procedures followed were in accordance with the ethical standards of the Medical Ethical Committee at National Research Centre, Cairo, Egypt and with the Helsinki Declaration of 1975, as revised in 2008. Informed consent was obtained from all patients included in this study. Confidentiality of records is saved by keeping the records anonymous.

\section{Blood collection and separation}

Four ml of venous blood were drawn from the both patients and control subjects. Two ml of blood were taken on EDTA containing tube for immunophenotyping (measurement of CD4,CD8 and CD19). Another two ml of blood were evacuated into a plain tube, allowed to clot for 30 minutes after collection then centrifuged at $3000 \mathrm{rpm}$ for 15 minutes to separate the serum, then the serum was kept frozen at $-70^{\circ} \mathrm{C}$ for determination of interleukin-2 level (Chan and perlstein, 1987).

\section{Serum Biochemical Analysis}

CD4, CD8 and CD19 were determined by flow cytometer(FACSCalibur BD bioscience, USA).

Interleukin 2:Human IL-2 ELISA kit KOMA BIOTECH INC.Catalog No. K0331193 contains all the necessary reagents required for performing quantitative measurement of Human IL-2 levels from samples including serum, plasma, culture medium or other biological fluids in a sandwich ELISA format.

pseudocholine esterase pseenzyme level ELISA kits: the kits were obtained from diamond diagnostcs company.

\section{Statistical analysis}

The collected data of clinical and laboratory results were organized, tabulated and statistically analyzed using SPSS software statistical computer package version 19. Data were expressed as Mean \pm Standard Deviation (SD). Independent sample- $t$ test 
was used to differentiate between two means where probability $(\mathrm{P}) ; \mathrm{P}<0.05$ : was considered significant and if $\mathrm{P}<0.01$ was considered highly significant. Quisquare test was used to test the statistical significance of differences in a classification system i.e. determine whether there is a significant association between two variables. The Correlation coefficient (r)isa correlation that describes the degree of relationship between two variables. Correlations were estimated using Pearson's test where probability $(\mathrm{P}): \mathrm{P}<0.05$ was considered significant.A positive correlation coefficient means that as the value of one variable increases, the value of the other variable increases; as one decreases the other decreases. A negative correlation coefficient indicates that as one variable increases, the other decreases, and vice-versa.

\section{Results}

Demographic data from history (tables 1, 2, 3 \& 4)

A significant statistical increase in number of male cases $(72.7 \%)$ than female $(23.3 \%)$ cases was observed. The mean age of patients was 30.1 \pm 8.5 years as shown in table (17). The cases in age group (18-27 years)were $(42.4 \%)$, those in age group (2837 years) were $(33.3 \%)$, while those in age group (3845 years) were (24.2\%).Number of suicidal cases was (69.7\%), while that of accidental cases was (30.3\%) of cases. There was a highly significant statistical increase in cases intoxicated by ingestion route (81.8\%) than other routes i.e. dermal and inhalation (12.1\%\& $6.1 \%$ respectively).The mean interval between malathion ingestion and patient arrival to P.C.C was $8.3 \pm 5.8$ hours as shown in table (17). Significant statistical difference in delay time of admission of malathion intoxicated patients as cases came after a delay time 5-12 hours were (54.5\%), those came after a delay $\leq 4$ hours were $(27.3 \%)$ and those came after a delay 12-24 hours were (18.2\%).

\section{Clinical picture results (tables 5, 6)}

Regarding vital signs, a significant statistical change in cases presented with malathion intoxication where tachycardia (66.7\%), normal blood pressure (51.5\%), normal temperature (63.6\%) and normal respiratory rate $(78.8 \%)$ were the predominant signs. Local manifestations showed highly significant statistical change aslacrimation, salivation and sweating occurred in (78.8\%) of cases. As regards systemic manifestations, a highly significant statistical difference was found that miosis (84.8\%), urinary incontinence (78.8\%), vomiting and diarrhea (87.9\%), chest crepitations and wheezes (81.8\%) occurred in these cases. Significant statistical difference regarding muscle twitches (72.7\%) and muscle weakness

Table (1): Sex distribution of malathion intoxicated cases.

\begin{tabular}{|c|c|c|}
\hline \multirow{2}{*}{ Sex } & \multicolumn{2}{|c|}{ Cases } \\
\cline { 2 - 3 } & $\mathbf{N}$ & $\mathbf{\%}$ \\
\hline Male & 24 & 72.7 \\
\hline Female & 9 & 27.3 \\
\hline Chi-square & \multicolumn{2}{|c|}{5.9} \\
\hline P value & \multicolumn{2}{|c|}{$0.014^{*}$} \\
\hline
\end{tabular}

$N$ (number of cases), $P$-value calculated by Chi-square test, $*=$ significant $(P$-value $<0.05)$
(69.7\%). Cases with intact sensorium were $48.5 \%$ of all patients. Coma presented in $33.3 \%$ of case, while convulsion presented in $18.2 \%$ of cases.

Laboratory investigation results (tables 7, 8, 9, 10, 11\& figs.1, 2, 3, 4)

Group Bsubjects showed statistically significant decrease in CD4 cellcount $(\mathrm{P}<0.001)$ after acute malathion toxicitywhen compared with group $\mathrm{A}$ controls. The reduced CD8 cellcount was found to be with statistically significant reduction $(\mathrm{P}<0.001)$ in group $\mathrm{B}$ subjects after acute malathion toxicityas compared to controls. CD19 cell level wasfound to be of highly significant decrease $(\mathrm{P}<0.001)$ in group $\mathrm{B}$ subjects after acute malathion toxicitywhen compared to control. On the other hand, a significant increase was observed in the interleukin IL-2 levels $(P \leq 0.05)$ of group $B$ subjects after acute malathion toxicitywhen compared with control (Table 2\& Fig. 4).Pseudocholine esterase mean was $1257.6 \pm 603.7$ IU/l as shown in table (17) and itslevel showed statistically significant difference between its subgroups as level $1000-1400 \mathrm{IU} / \mathrm{ml}$ was the most predominant level (45.4\%).Significant positive correlation was observed between IL-2 \& CD4 i.e. when IL-2 level increases CD4 count increases. Insignificant statistical correlation between IL-2 and CD8 was seen. Highly significant statistical negative correlation between IL-2 and CD19 was noticed i.e. when IL-2 level increases CD19 count decreases. No significant statistical correlation between pseudocholine esterase level and (CD 19, CD8 \& CD4)

Treatment results (tables 12, 13, 14, 15)

Out of malathion intoxicated patients (27.3\%) of cases were admitted at ICU as critical cases. The mean value of atropine ampoules was $11.6 \pm 4.3$ ampoules as shown in table (17). Using 10-15 ampoules of atropine was the most common used dose in this study (45.5\%) with significant statistical difference when compared with other doses. The mean value of toxogonin ampoules was $7.5 \pm 3.2$ ampoules as shown in table (17). Administration of 5-9 toxogonin ampoules represented (54.5\%) of toxogonin doses and showed significant statistical difference when compared with other doses. The mean duration of patients' hospital stay was $8.6 \pm 4.8$ days as shown in table (17). Admission for 4-7 days was the most common hospital stay duration (36.4\%).

\section{Mortality rate and cause results (table 16)}

Out of 33 cases, 3 cases died $(9.1 \%)$ as a result of adult respiratory distress syndrome (ARDS). 
Table (2): Age distribution of malathion intoxicated cases.

\begin{tabular}{|c|c|c|}
\hline \multirow{2}{*}{ Age group (years) } & \multicolumn{2}{|c|}{ Cases } \\
\cline { 2 - 3 } & $\mathbf{N}$ & $\mathbf{\%}$ \\
\hline $18-27$ & 14 & 42.4 \\
\hline $28-37$ & 11 & 33.3 \\
\hline $38-45$ & 8 & 24.3 \\
\hline Chi-square & \multicolumn{2}{|c|}{1.6} \\
\hline P value & \multicolumn{2}{|c|}{0.441} \\
\hline
\end{tabular}

$N$ (number of cases), $P$-value calculated by Chi-square test, $P$-value $>0.05$ (non-significant)

Table (3): Mode of toxicity in malathion intoxicated cases.

\begin{tabular}{|c|c|c|}
\hline \multirow{2}{*}{ Mode of toxicity } & \multicolumn{2}{|c|}{ Cases } \\
\cline { 2 - 3 } & $\mathbf{N}$ & $\mathbf{\%}$ \\
\hline accidental & 10 & 30.3 \\
\hline Suicidal & 23 & 69.7 \\
\hline Chi-square & \multicolumn{2}{|c|}{4.4} \\
\hline P value & \multicolumn{2}{|c|}{$0.036^{*}$} \\
\hline
\end{tabular}

$N$ (number of cases), $P$-value calculated by Chi-square test, $*=$ significant $(P$-value $<0.05)$

Table (4): Route of toxicity in malathion intoxicated cases.

\begin{tabular}{|c|c|c|}
\hline \multirow{2}{*}{ Route of intoxication } & \multicolumn{2}{|c|}{ Cases } \\
\cline { 2 - 3 } & $\mathbf{N}$ & $\mathbf{\%}$ \\
\hline Ingestion & 27 & 81.8 \\
\hline Dermal & 4 & 12.1 \\
\hline inhalation & 2 & 6.1 \\
\hline Chi-square & \multicolumn{2}{|c|}{35.1} \\
\hline P value & \multicolumn{2}{|c|}{$<0.001 * *$} \\
\hline$N$ (number of cases), P-value calculated by Chi-square test, $* *=P$-value $<0.01$ (highly significant)
\end{tabular}

Table (5): Delay time in patient presentation of malathion intoxicated cases.

\begin{tabular}{|c|c|c|}
\hline \multirow{2}{*}{ Delay time (hours) } & \multicolumn{2}{|c|}{ Cases } \\
\cline { 2 - 3 } & $\mathbf{N}$ & $\mathbf{\%}$ \\
\hline$\leq 4$ & 9 & 27.3 \\
\hline $5-12$ & 18 & 54.5 \\
\hline $12-24$ & 6 & 18.2 \\
\hline Chi-square & \multicolumn{2}{|c|}{7.1} \\
\hline P value & \multicolumn{2}{|c|}{$0.028^{*}$} \\
\hline
\end{tabular}

$N$ (number of cases), $P$-value calculated by Chi-square test, *: $P$-value $<0.05$ (significant) 
Table (6): Clinical picture in malathion intoxicated cases.

\begin{tabular}{|c|c|c|c|c|c|}
\hline \multicolumn{2}{|c|}{ Clinical manifestation } & $\mathbf{N}$ & $\%$ & Chi-square & P value \\
\hline \multicolumn{6}{|c|}{ Vital signs } \\
\hline \multirow[t]{3}{*}{ pulse } & Tachycardia & 22 & 66.7 & \multirow[t]{3}{*}{16.9} & \multirow[t]{3}{*}{$0.002 * *$} \\
\hline & Bradycardia & 7 & 21.2 & & \\
\hline & Normal & 4 & 12.1 & & \\
\hline \multirow[t]{3}{*}{ Blood pressure } & Normal & 17 & 51.5 & \multirow[t]{3}{*}{6.5} & \multirow[t]{3}{*}{$0.037^{*}$} \\
\hline & Hypertensive & 5 & 15.2 & & \\
\hline & Hypotensive & 11 & 33.3 & & \\
\hline \multirow[t]{3}{*}{ Temperature } & Normal & 26 & 78.8 & \multirow[t]{3}{*}{31.1} & \multirow[t]{3}{*}{$<0.001 * *$} \\
\hline & Hypothermia & 5 & 15.2 & & \\
\hline & Hyperthermia & 2 & 6.1 & & \\
\hline \multirow[t]{3}{*}{ Respiratory rate } & Normal & 21 & 63.6 & \multirow[t]{3}{*}{14.4} & \multirow[t]{3}{*}{$<0.001 * *$} \\
\hline & Tachypnea & 8 & 24.2 & & \\
\hline & Bradypnea & 4 & 12.1 & & \\
\hline \multicolumn{6}{|c|}{$\begin{array}{l}\text { Local manifestations } \\
\end{array}$} \\
\hline Skin, mucous membrane, eye & Lacrimation, sweating and salivation & 26 & 78.8 & 9.8 & $0.001 * *$ \\
\hline \multicolumn{6}{|c|}{ Systemic manifestations } \\
\hline \multirow[t]{3}{*}{ CNS } & Convulsions & 6 & 18.2 & \multirow[t]{3}{*}{4.5} & \multirow[t]{3}{*}{0.103} \\
\hline & Coma & 11 & 33.3 & & \\
\hline & Intact sensorium & 16 & 48.5 & & \\
\hline \multirow[t]{2}{*}{ Eye } & Miosis & 28 & 84.8 & \multirow[t]{2}{*}{147} & \multirow[t]{2}{*}{$<0.001 * *$} \\
\hline & Normal & 5 & 15.2 & & \\
\hline GIT & Vomiting and diarrhea & 29 & 87.9 & 17.4 & $<0.001 * *$ \\
\hline Urinary & $\begin{array}{l}\text { Incontinence } \\
\end{array}$ & 26 & 78.8 & 9.8 & $0.001^{* *}$ \\
\hline Respiratory & Chest crepitation and wheezes & 27 & 81.8 & 12.1 & $<0.001 * *$ \\
\hline \multirow[t]{2}{*}{ Musculoskeletal } & Muscle twitches & 24 & 72.7 & 5.9 & $0.014 *$ \\
\hline & Muscle weakness & 23 & 69.7 & 4.4 & 0.036* \\
\hline
\end{tabular}

$N$ (number of cases), $P$-value calculated by Chi-square test, *: $P$-value $<0.05$ (significant),

**: P-value $<0.01$ (highly significant), P-value $>0.05$ (non-significant).

Table (7): Independent sample t-test showing CD4,CD8, CD19 cell count (cell/cc ${ }^{3}$ )of group A and group B subjects after acute malathion toxicity.

\begin{tabular}{|c|c|c|c|}
\hline Parameter & Control & Patient & P-value \\
\hline CD4 $\left(\right.$ cell/cc $\left.{ }^{3}\right)$ & $41.59 \pm 4.05$ & $25.27 \pm 3.38$ & $<0.001^{* *}$ \\
\hline CD8 $\left(\right.$ cell/cc $\left.{ }^{3}\right)$ & $32.07 \pm 3.91$ & $14.82 \pm 2.40$ & $<0.001^{* *}$ \\
\hline CD 19 $($ cell//cc $)$ & $19.21 \pm 4.52$ & $9.55 \pm 1.37$ & $<0.001^{* *}$ \\
\hline
\end{tabular}

**: $p$ value $<0.01$ (highly significant). Values were expressed as mean \pm standard deviation, cc $^{3}=$ cubic centimeter. $^{2}$

Table (8): Independent sample t-test of IL2 levelws (pg/ ml) of group A subjects (control) and group B (patients) after acute malathione toxicity.

\begin{tabular}{|c|c|c|c|}
\hline parameter & Control & Patient & P-value \\
\hline IL-2 $(\mathrm{pg} / \mathrm{ml})$ & $20.30 \pm 4.22$ & $78.19 \pm 16.74$ & $<0.001^{* *}$ \\
\hline **: $p$ value $<0.01$ (highly significant). Values were expressed as mean \pm standard deviation
\end{tabular}

Table (9): Pseudocholine esterase level in malathion intoxicated cases.

\begin{tabular}{|c|c|c|}
\hline \multirow{2}{*}{ Pseudocholine esterase level (IU/ml) } & \multicolumn{2}{|c|}{ Cases } \\
\cline { 2 - 3 } & $\mathbf{N}$ & $\mathbf{\%}$ \\
\hline$>2600$ & 2 & 6.1 \\
\hline $1400-2600$ & 7 & 21.2 \\
\hline $1000-1400$ & 15 & 45.4 \\
\hline$\leq 1000$ & 9 & 27.3 \\
\hline Chi-square & \multicolumn{2}{|c|}{8.6} \\
\hline P value & \multicolumn{2}{|c|}{$0.035^{*}$} \\
\hline
\end{tabular}

$N$ (number of cases), $P$-value calculated by Chi-square test, *: $P$-value $<0.05$ (Significant) 
Table (10): Correlation between IL-2 and some parameters (CD 19, CD8 and CD4)

\begin{tabular}{|c|c|c|c|}
\hline \multirow{2}{*}{ parameter } & \multicolumn{2}{|c|}{ IL-2 } & \multirow{2}{*}{ Sig. } \\
\cline { 2 - 4 } & $\mathrm{r}$ & P value & S \\
\hline CD4 & 0.3 & $0.043^{*}$ & NS \\
\hline CD8 & 0.2 & 0.199 & HS \\
\hline CD 19 & -0.5 & $0.002^{* *}$ & NS \\
\hline
\end{tabular}

$r=$ Correlation coefficient, $P$-value calculated by Pearson's correlation, $S$ or *: P-value < 0.05 (significant), HS or **: $P$-value $<0.01$ (highly significant),NS: P-value $>0.05$ (non-significant).

Table (11): Correlation between pseudocholine esterase level and (CD 19, CD8 \& CD4)

\begin{tabular}{|c|c|c|c|}
\hline \multirow{2}{*}{} & \multicolumn{2}{|c|}{ Pseudocholine esterase level } & \multirow{2}{*}{ Sig. } \\
\cline { 2 - 4 } & $\mathrm{r}$ & P value & NS \\
\hline CD 19 & -0.2 & 0.253 & NS \\
\hline CD8 & 0.1 & 0.433 & NS \\
\hline
\end{tabular}

$r=$ Correlation coefficient, $P$-value calculated by Pearson's correlation, *: P-value < 0.05 (significant), **: P-value < 0.01 (highly significant), $P$-value $>0.05$ (non-significant).

Table (12): Grading of malathion intoxicated cases.

\begin{tabular}{|c|c|c|}
\hline Grading of cases & $\mathbf{N}$ & $\mathbf{\%}$ \\
\hline Critical cases & 9 & 27.3 \\
\hline Non critical cases & 24 & 72.7 \\
\hline Chi-squared & \multicolumn{2}{|c|}{5.9} \\
\hline P value & \multicolumn{2}{|c|}{$0.014^{*}$} \\
\hline
\end{tabular}

$N$ (number of cases), $P$-value calculated by Chi-square test, *: $P$-value $<0.05$ (significant)

Table (13): Atropine dose in malathion intoxicated cases.

\begin{tabular}{|l|l|l|}
\hline \multirow{2}{*}{ No. of vials } & Cases \\
\cline { 2 - 3 } & $\mathbf{N}$ & $\mathbf{\%}$ \\
\hline$\leq 4$ & 3 & 9.1 \\
\hline $5-9$ & 7 & 21.2 \\
\hline $10-15$ & 15 & 45.5 \\
\hline$>15$ & 8 & 24.2 \\
\hline Chi-square & 9.1 & \\
\hline P value & $0.028^{*}$ \\
\hline
\end{tabular}

$N$ (number of cases), $P$-value calculated by Chi-square test, $P$-value $>0.05$ (non-significant)

Table (14): Toxogonin dose in malathion intoxicated cases.

\begin{tabular}{|l|l|l|}
\hline \multirow{2}{*}{ No. of vials } & Cases & \multicolumn{1}{|l|}{} \\
\cline { 2 - 3 } & $\mathbf{N}$ & $\mathbf{\%}$ \\
\hline$\leq 4$ & 9 & 27.3 \\
\hline $5-9$ & 18 & 54.5 \\
\hline $10-12$ & 6 & 18.2 \\
\hline Chi-square & 7.1 & \\
\hline P value & $0.028^{*}$ \\
\hline
\end{tabular}

$N$ (number of cases), $P$-value calculated by Chi-square test, $P$-value $>0.05$ (non-significant)

Table (15): Hospital stay duration (days) in malathion intoxicated cases.

\begin{tabular}{|l|l|l|}
\hline \multirow{2}{*}{ Hospital stay duration (days) } & \multicolumn{2}{l|}{ Cases } \\
\cline { 2 - 3 } & $\mathbf{N}$ & $\mathbf{\%}$ \\
\hline$\leq 3$ & 4 & 12.1 \\
\hline $4-7$ & 12 & 36.4 \\
\hline $8-14$ & 11 & 33.3 \\
\hline$\geq 15$ & 6 & 18.2 \\
\hline Chi-square & 5.4 & \\
\hline P value & 0.143 \\
\hline
\end{tabular}

$N$ (number of cases), $P$-value calculated by Chi-square test, $P$-value $>0.05$ (non-significant) 
Table (16): Mortality ratein malathion intoxicated cases.

\begin{tabular}{|l|l|l|}
\hline cases & $\mathbf{N}$ & $\mathbf{\%}$ \\
\hline Died cases & 3 & 9.1 \\
\hline Live cases & 30 & 90.9 \\
\hline Chi-squared & 20.4 & \\
\hline P value & $<0.001^{* *}$ & \\
\hline
\end{tabular}

$N$ (number of cases), $P$-value calculated by Chi-square tes, ${ }^{* *}: P$-value $<0.01$ (highly significant), ARDS =adult respiratory distress syndrome.

Table (17): Mean values of some parametersin malathion intoxicated cases.

\begin{tabular}{|l|l|}
\hline parameter & Mean \pm S.D \\
\hline Age (Year) & $30.1 \pm 8.5$ \\
\hline Delay time (hours) & $8.3 \pm 5.8$ \\
\hline Atropine dose & $11.6 \pm 4.3$ \\
\hline Oxime dose & $7.5 \pm 3.2$ \\
\hline Hospital stay duration (days) & $8.6 \pm 4.8$ \\
\hline Pseudocholine esterase level & $1257.6 \pm 603.7$ \\
\hline
\end{tabular}

$S . D=$ standard deviation

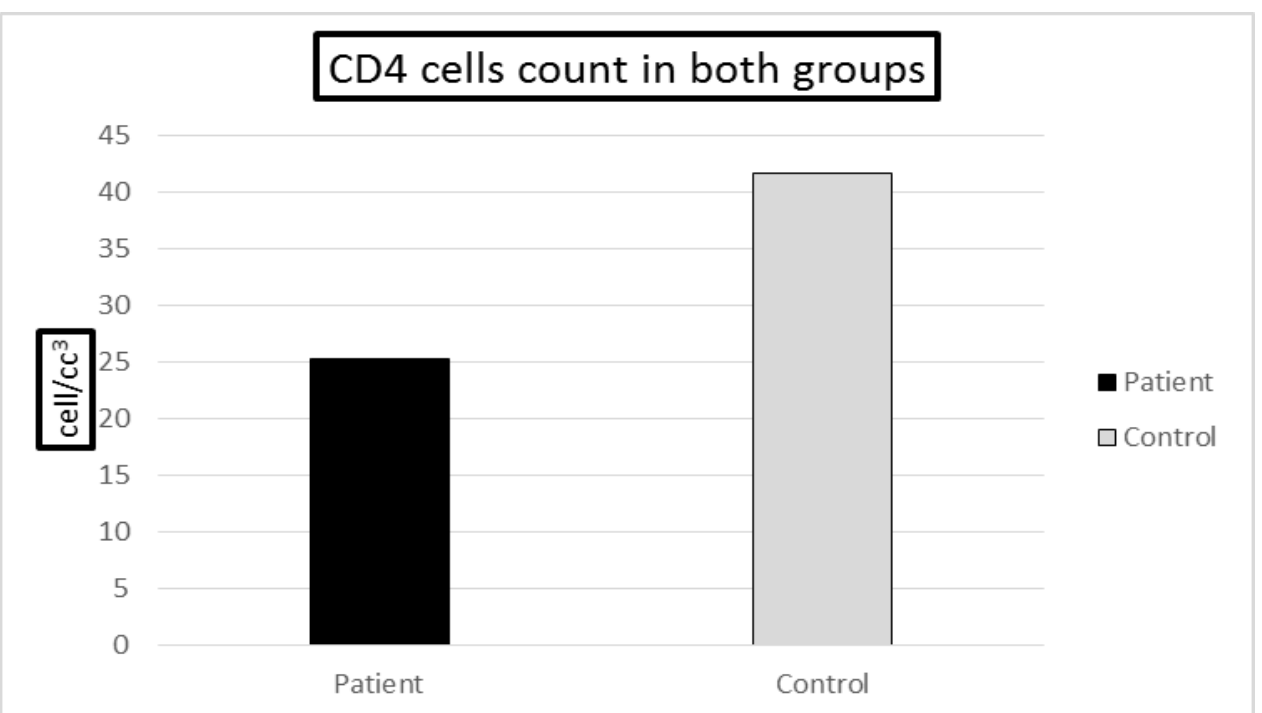

Fig. 1. Showing mean of CD4 cell count of groups B (patients) and group A (control).

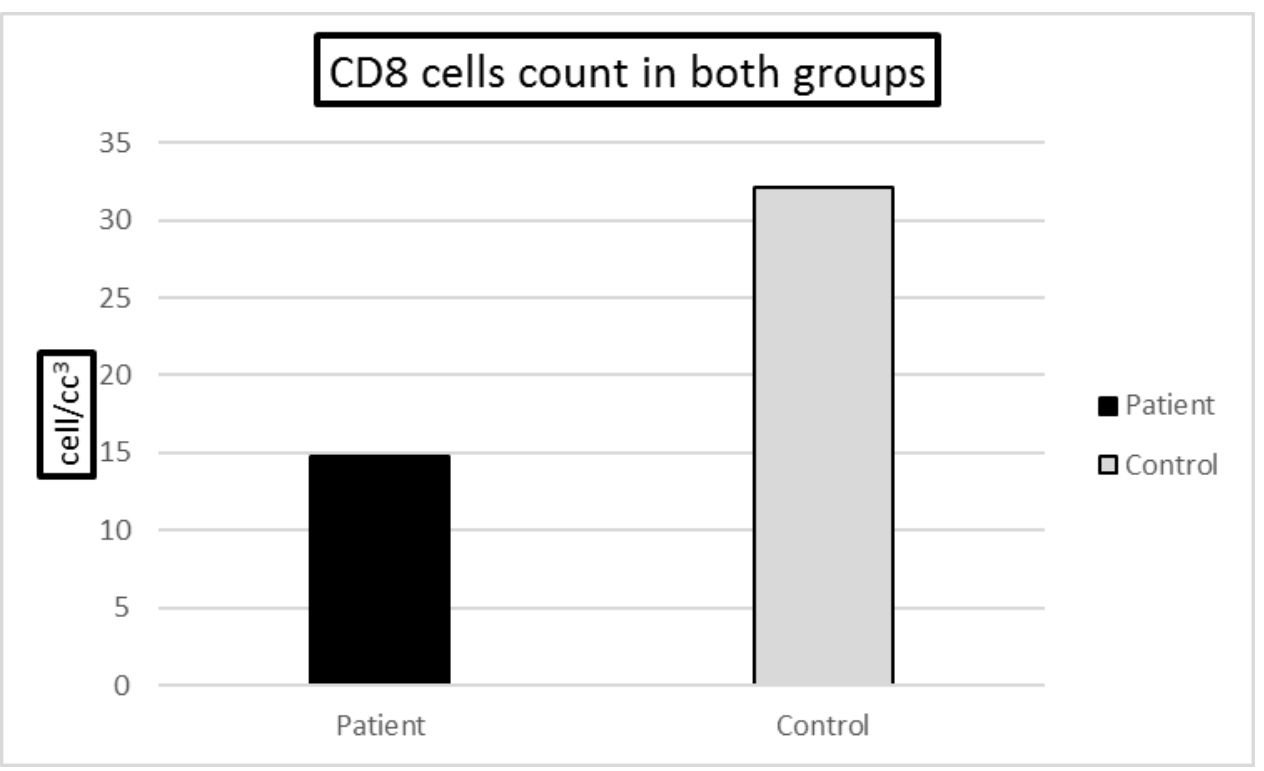

Fig. 2. Showing mean of CD8 cell count of groups B (patients) and group A (control) 


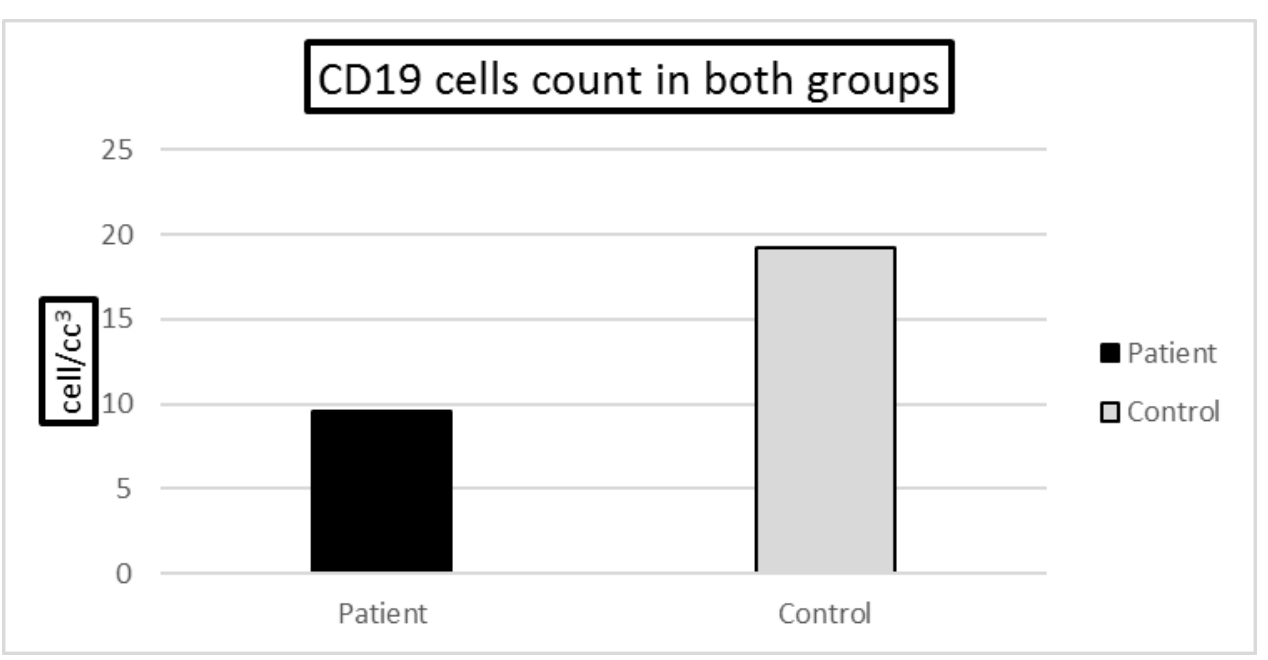

Fig. 3. Showing mean of CD19 cell count of groups B (patients) and group A (control).

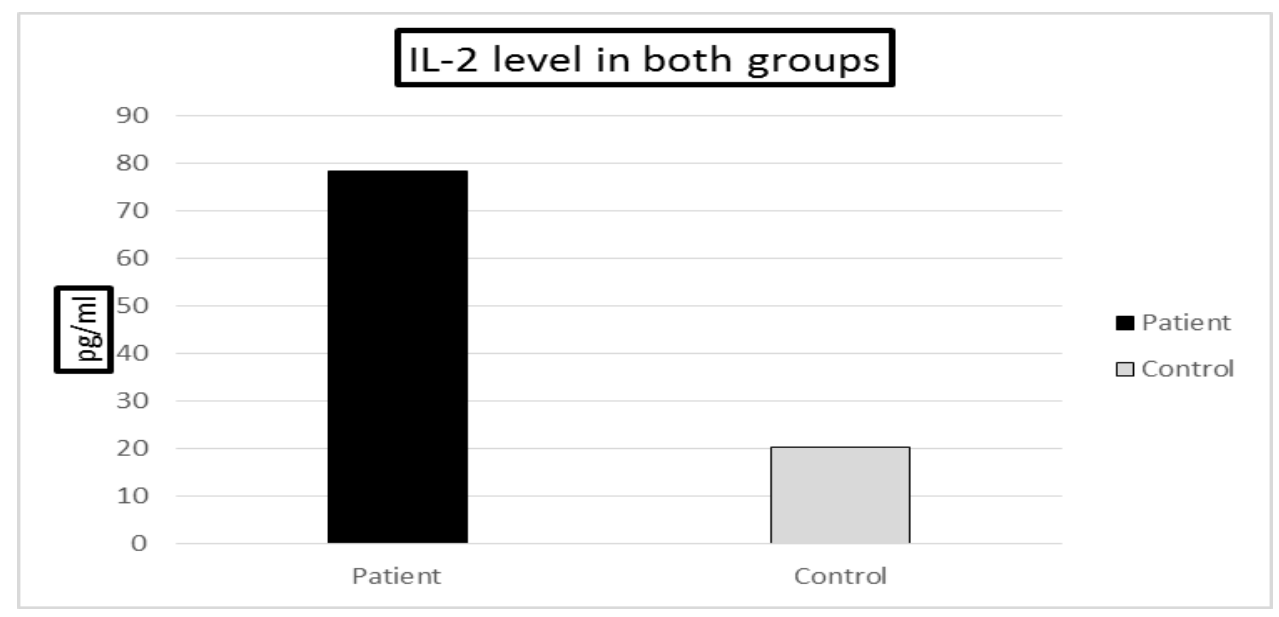

Fig. 4. Showing mean of IL2 level (pg/ml) of groups B (patients) and group A subjects (control).

\section{Discussion}

Organophosphorus pesticides (OPs) are widely used throughout the world as insecticides in agriculture and as eradicating agents for termites(Corsini et al., 2013).Among them, malathion is widely used and legally allowed by ministry of agriculture in Egypt to control pests which attack several important crops(Amer et al., 2002).

Several pesticides, including organophosphate compounds have the potentiality to produce immunotoxicity. The immune response plays an important role in the pathophysiology of numerous diseases(Corsini et al., 2013).

The current study was carried out todemonstrate some clinical effects and to investigate some biochemical changes associated with acute malathion (one type of organophosphorus insecticide) intoxication on the immune system.

Our clinical study depended on the work ofCorsini et al., (2008)who reported that the first phase of immunotoxicity studies should include the determination of CD3, CD4, CD8 (CD4/ CD8 ratio), CD19 and CD16/56 positive cells.

Regarding demographic data, the current study revealed that malecases $(72.7 \%)$ were more than female cases(27.3\%). This finding is in agreement with study conducted in Chennai by Shivaprasad et al., (2001), in which male patients (74\%) outnumbered female (26\%). However, in a study conducted in Nepal male: female was1:2 (Rehiman et al., 2008). This may be explained by the fact that the majority of male cases were farmers who usually handle with organophosphus insecticides.

The mean age of cases was $(30.1 \pm 8.5)$ years and the majority of affected patients belong to age group (18-27) years (42.4\%).Banerjee et al., (2012) reported that majority of the patients belonged to the young age group (Mean \pm S.D.: $34.47 \pm 9.21$ ).

Suicidal intent was the most common mode of toxicity (69.7\%) while, accidental one was (30.3\%). This result approximately similar to Banerjee et al., (2012) who reported that poisoning with suicidal intent (82.02\%) was more common than the accidental one (17.98\%).

The majority of affected patients were intoxicated by ingestion route (81.8\%). Yuruzem et al., (2008) demonstrate that oral ingestion (86.5\%) was 
found to be the most common route of poisoning.

The mean interval between intoxication and admission to the hospital was 8.3 hours and the maximum number of patients $(54.5 \%)$ presented with delay 5-12 hrs. In a study conducted at Chennai, maximum patients (89.69\%) presented within 6 hours(Shivakumaret al., 2002). This delay can be attributed to living of farmers in villages where they go to primary health care unit at first before going to P.C.C of Minia University Hospital which is tertiary health care.

Tachycardia (66.7\%), normal blood pressure (51.5\%), normal temperature (78.8\%), normal respiratory rate $(63.6 \%)$ were the evident vital signs in our study. Banerjee et al., (2012) reported that bradycardia represented (38\%), tachycardia (8\%), hypothermia (6\%) and hypertension (9\%) while Rehiman et al., (2008) showed thatbradycardia represented (52\%), tachypnea (34\%).

Lacrimation, salivation \& sweating occurred in $(78.8 \%)$ of caseswith statistically significant difference. Gannur et al., (2008) reported that salivation developed in (68\%) of cases.

Intact sensorium (48.5\%), miosis (84.8\%), vomiting and diarrhea (87.9\%), urinary incontinence (78.8\%), chest crepitation and wheezes (81.8\%), muscle twitches (72.7\%) and muscle weakness (69.7\%) were the commonest systemic manifestations and occurred with statistically significant difference. Gannur et al., (2008), reported that miosis (74\%), diarrhea (17\%), convulsions (4.92\%) developed. Chugh et al., (2005) reported that vomiting (80\%), convulsions (26.6\%), incontinence (40\%), miosis (100\%), muscle twitches (40\%).

The variability in the clinical presentation depends on nature of organophosphorus insecticides compounds, amount consumed, the type of exposure, the quantity absorbed, and time gap between exposure and presentation in the hospital (Eddleston, 2008; Paudyal, 2008).

Pseucholinestrase enzyme levels were significantly reduced with mean value $(1257.6 \pm 603.7$ $\mathrm{U} / \mathrm{l})$ and most cases were in the group level 1000-1400 U/l. Significant decrease was observed in acetylcholinesteraseactivity in RBC of malathion poisoning cases in comparison to control subjects (Vandana et al., 2008). The decrease of this enzyme can be explained as malathion like other organophosphoruscompounds inhibit acetylcholinesterase enzyme resulting in accumulation of acetylcholine (Ach) and overstimulation of cholinergic synapses (Eddleston, 2008).

CD4 $\mathrm{T}$ cells are mainly cytokine-secreting helper cells (CD4+ lymphocytes) that play an important role in maximizing the capabilities of the acquired immune response.CD4 T helper cells can be divided into two major types;type 1 (Th1) helper T cells secrete interleukin- 2 and interferon (IFN)andtype 2 (Th2) helper $\mathrm{T}$ cells secrete interleukin-4, 5, 6, and 10 (Yazawa et al., 2003).

CD8 T cells (Cytotoxic T lymphocyte, CD8+) induce death of cells that are damaged, dysfunctional and infected with viruses or pathogens. CD19 B cells are B-lymphocytes. CD19 is an antigen, found on the surface of B-cells. CD19 cells regulate innate immunity(Yazawa et al., 2003).

Cytokines (e.g. IL-2) are specific chemical mediators which have a central role in the immune response as a protection against infectious agents and reduction of allergic and autoimmune responses (Gately et al., 1998).

The current study revealed statistically significant decrease in the levels of CD4, CD8 and CD19. These results are in agreement with those of El Sharkawy et al., (2003)who reported that the effect of malathion on the percentage of T-lympocytes blastogenesis in response to PHA (phytoheamoagglutinin) mitogen stimulation revealed highly significant decrease in lymphocyte percentage.

The previous findings can be explained as follow: 1)Malathion acts directly or indirectly on lymphoid cell distribution, Ig metabolism, T or B cell functions, macrophages cooperation and macromolecular biosynthesis (Zabrudski et al., 2003).2) Immune suppression after malathion exposure is possible as organophosphates bind to esterase, a vital membrane bound protein that helps immune cells to interact with and destroy foreign organisms ( $\mathrm{Li}$ et al., 2006). 3)These effects may be free radicals-mediated as several studies suggest that cytokines are at times released during oxidative stress (Krieger et al., 1998).

As regards IL-2 levels, our study revealed a significant increase in IL-2 levels $(\mathrm{P}<0.05)$ in group $\mathrm{B}$ subjects, in comparison with group $\mathrm{A}$, after acute malathion toxicity. Our findings are in accordance with Vandana et al., (2008) who noticed an elevation of IL-2 levels in their research. Our results are not in accordance with (Barnett and Rodgers, 1994; andelbriel et al. 2000) who showed decreased IL-2 production in rats.Vandana et al., (2008)suggested thatthe increase in IL-2 was due to interaction between malathion and early stage of lymphocyte activation, so increased IL-2 level wasa result of proliferation of T cells. In addition, they stated that cytokines are specific cellular mediators of immune system, synthetized by lymphoid cells and non-lymphoid cells and bind to specific receptors on the target cells.Malek, (2008) reported that although previous studies of this cytokine have focused primarily on T-cells, new findings have highlighted that IL-2 is also produced by other cell types (e.g. dendritic cells) and in various different settings. For these reasons, IL-2 can be defined as a pleiotropic cytokine with different functions.

A positive significant correlation between IL2 and CD4was elucidated.Type 1 (Th1) CD4 T helper cells secrete interleukin-2 so, the increase in CD4 T cells is associated with increase IL-2 level (Yazawa et al., 2003).

Positive insignificant correlation between IL-2 and CD8. Cytotoxic T lymphocyte, (CD8+) induce death of cells(Yazawa et al., 2003). So, CD8 does not involved in IL-2 secretion and this may explain 
insignificant correlation.

A negative significant correlation between IL2 and CD19 were observed. This finding may be due to presence of other cytokine that affect B lymphocyte maturation and activation.Malathion modulates immune response. Th1-like response is enhanced with release of cytokines IFN \& IL-2. IL-2induces B cell maturation. Th2-derived IL-4 stimulates B cell activation and Ig secretion, and Th1-derived IFN causes antagonistic response. Th2 response is partially inhibited with decreased IFN production as a result of Ach accumulation. So, the end result is reduction of CD19 count although elevation in IL-2 level (Spergel et al., 1999).

Insignificant statistical correlation betwe en pseudocholine esterase enzyme and CD4, CD8, CD19 and IL-2. This result disagrees with Galloway et al., (2004) who reported that a correlation between PChE suppression and immune responses by organophosphates has been suggested. The decreased activity of AChE after malathion exposure inhibits the E-rosetting of T-lymphocytes Moreover, inhibition of AChE results in an accumulation of the amino acid neurotransmitter acetylcholine (ACh), which stimulates lymphocytes, elevates concentrations of cellular c-GMP and increases the motility and cytotoxicity of lymphocytes leading to reduction in the IFN levels in serum. The difference between 2 studies may be due to many factors as malathion concentration, administered amount, bioavilability of malathion.

In our study, critical cases that were admitted at ICU represented (27.3\%) of all cases. Çolaket al., (2014) reported that (15\%) patients were admitted to the intensive care unit. Early admission to hospital and receiving first aid and specific measures as emisis, gastric lavage and antidote therapy (atropine \& oxime) may explain the decrement in severe and critical cases in Çolaket al., (2014) in comparison to our study result.

The mean value of atropine ampoules was 11.6 \pm 4.3 ampoules and using 10-15 ampoules of atropine was the most common used dose in this study (45.5\%) with significant statistical difference when compared with other doses. The mean value of toxogonin ampoules was 7.5 \pm 3.2 ampoules. Administration of 5-9 toxogonin ampoules represented (54.5\%) of toxogonin doses and showed significant statistical difference when compared with other doses. The mean duration of patients' hospital stay was 8.6 \pm 4.8 days. Admission for 4-7 days was the most common hospital stay duration (36.4\%).

The need for high doses of atropine andtoxogonin and prolonged hospital stay may be a result of delayed presentation of most patients as the mean value of delay in this study reached 8.3 hours giving malathion more time to cause more morbidity in patients.

Out of 33 cases,3patients of malathion toxicity died (9.1\%) due to ARDS that occurred as a complication of mechanical ventilation. This finding is comparable to the study done in Turkey where mortality rate was $(9.1 \%)$ and patients died due to sudden respiratory and cardiac arrest (45\%), respiratory failure (25\%), CNS depression (5\%) and septic shock (25\%). (Yurumez et al., 2007). Another study showed that following admission, a total of 56 (5.78\%) patients died during their hospital stay andrespiratory failure was the primary cause of death in 21 patients (37.5\%) followed by CNS depression (33.92\%), cardiac arrest (21.44\%), and septicemia (7.14\%)(Banerjee et al., 2012). The difference between studies regarding mortality rate can be attributed to delay presentation of patients and difference in malathion concentration, ingested amount \& absorbed fraction

\section{Conclusion}

The assessment of immunotoxicity in human is a very difficult task. Also, the assessment of the immunotoxicity of pesticides in agricultural settings, where co-exposures to several compounds is common, is needed. Acute malathion intoxication carries a risk of immunotoxicity as it affects $\mathrm{T}$ cells proliferation and secretion of cytokines i.e. IL-2. Due to the paucity of data, especially new pesticides, it is clear that there is demand to continue to improve immunotoxicology studies. A concerted effort is required to organize and standardize a study protocol.

\section{References}

Amer A, Fahmy M, Aly F, and Farghaly A. (2002):Cytogenic studies on the effect of feeding mice with stored wheat grains treated with malathion. Mut. Res. 513: 1-10.

Banerjee I, TripathSK , SinhaAR (2012):Clinicodemiological Characteristics of Patients Presenting with Organophosphorus PoisoningN Am J Med Sci.; 4(3): 147-150.

Barnett JB, and Rodgers KE. (1994): Pesticides. In:Immunotoxicology and Immunopharmacology. Dean J.H., Luster A.E., Munson A.E., and Kimber I. (eds), 2nd edition, Raven press, New York, USA. 191-212.

Chan and Perlstein (1987):Immunoassay: A Practical Guide, Chan and Perlstein, Eds., Academic Press: New York, p71.

Chugh SN, Aggarwal N, Dabla S, et al.,(2005):comparative evaluation of atropine alone and atropine with pralidoxime (PAM) in the management of organophosphorus poisoning. J Indian Acad Clin Med. ;6:33-7.

Çolak Ş, Mehmet ÖE, Ahmet B , et al., (2014): Epidemiology of organophosphate intoxication and predictors of intermediate syndrome, Turk. J. Med. Sci. 44: 279-282

CorsiniE, LiesivuoriJ, VergievaT, et al., (2008):Effects of pesticide exposure on the human immune system Hum. Exp. Toxicol., 27:671-680

Corsini E., Sokooti M., Galli C.L., et al., (2013). Pesticide induced immunotoxicity in humans: A comprehensive review of the existing evidence 
Eddleston M.(2008): The pathophysiology of organophosphorus pesticide self-poisoning is not so simple. Neth J Med. ;66:146-8.

El Sharkawy SA, Fargaly AM, Badary MS and Abdelall KM (2003): Immunologicalstudiesof malathion asanexampleofinsecticides AAMJ.Vol. 1, No. 1

Gannur DG, Maka P, Reddy N.(2008):Organophosphorus compound poisoning in Gulbargaregion - A five year study. Indian J Forensic Med Toxicol. .

Galloway T \& Handy R (2004):immunotoxixity of organophosphrus pesticides. Ecotoxicol12, 345-363

Gately MK, Renzetti LM, Magram J, et al. (1998):The interleukin-12/interleukin-12receptor system: role in normal and pathologic immune responses. Annu Rev Immunol.,16:495-521.

HoppinJ.A., ValcinM., HennebergerP.K., et al.,(2007):Pesticide use and chronic bronchitis among farmers in the Agricultural Health Study Am. J. Ind. Med., 50:969-979

International programme on chemical safety (IPCS), (2012): Guidance for immunotoxicity risk assessment for chemicals. Application of risk assessment principles to immunotoxicity,p:19.

JagaK, and Dharmani C. (2005):The epidemiology of pesticide exposure and cancer: a review Rev. Environ. Health, 20:15-38

Krieger J A, Heo Y, Lawrence D A (1998)In: oxidative stress and heavy metal modification of $\mathrm{T}$ lymphocyte(Kimber $\mathrm{J}$ \& Selgrade M K eds), pp 102-118

Li Bin, Duysen EG, Poluktova LYet al., (2006): Toxicol Appl Pharmacol. 214, 68198-68200

Malek T. R. (2008). The biology of interleukin2. Annu. Rev.Immunol. 26, 453-479 [PubMed]

McDuffie H.H. (2005):Host factors and genetic susceptibility: a paradigm of the conundrum of pesticide exposure and cancer associations Rev. Environ. Health, 20:77101

OrsiL., DelabreL., MonnereauA., et al., (2009):Occupational exposure to pesticides and lymphoid neoplasms among men: results of a French case-control study Occup. Environ. Med., 66:291-298

Paudyal BP. (2008): Organophosphorus poisoning. J Nepal Med Assoc. 47:251-8.

Persson EC, Graubard, BI, Evans AA, et al.,(2012):
Dichlorodiphenyltrichloroethane and risk of hepatocellular carcinoma. Int. J. Cancer, http://dx.doi.org/10.1002/ijc.27459.

Rehiman S, Lohani SP, Bhattarai MC. (2008): Correlation of serum cholinesterase level, clinical score at presentation and severity of organophosphorous poisoning. J Nepal Med Assoc. ;47:47-52.

Shivakumar S, Rajan SK, Madhu CR, et al. (2002): Profile of acute poisoning in Chennai: A two year experience in Stanley Medical College and Hospital (1999-2000). J. Assoc. Physicians India. ;50:206.

SlagerRE, SimpsonSL, LevanTD, et al.,(2010):Rhinitis associated with pesticide use among private pesticide applicators in the agricultural health study J. Toxicol. Environ. Health A, 73:1382-1393

Spergel JM, Mizoguchi E, Oe tlgen Het al., (1999):role of Th1 and Th2 cytokines in a murine model of allergic dermatitis. J. Clin. Invest. 3, 1103-1111

SunyerJ, Garcia-EstebanR, AlvarezM, et al.,(2010):DDE in mothers' blood during pregnancy and lower respiratory tract infections in their infants Epidemiology, 21:729-735

Van Loveren H, Van Amsterdam JG, Vandebriel RJ, et al.(2001): Vaccine-induced antibody responses as parameters of the influence of endogenous and environmental factors. Environ Health Perspect. 109: 757-764.

Vandana Seth, Banerjee BD, Rafat S A,et al., (2008): Alteration in immunoglobulins and cytokine levels in blood of malathion poisoning cases. Indian Journal of Biochemistry \& Biophysics, 45:209-211

Vanderbriel RJ, Meredith C, Scott MP, et al., (2000): Interleukin-10 is an unequivocal th2 parameter in the rat, whereas interleukin-4 is not. Scan. J. Immunol. 52(5): 519-524.

Yazawa N, Fujimoto M, Sato S, et al., (2003):CD19 regulates innate immunity by the toll-like receptor RP105 signaling in B lymphocytes.Blood. Aug 15; 102 (4): 137480.

Yurumez Y, Durukan P, Yavuz Y, et al.(2007): Acute organophosphate poisoning in university hospital emergency room patients.Intern Med. ;46:965-9.

Zabrodskii P F, Germanchuk V G, Kirichuk V F, et al., (2003):Anticholinesterase mechanism as a factor of immunotoxicity of various chemical compounds.Bull Exp Biol Med 136,

176-178. 


\section{الملخص العربي}

بعض التأثيرات الاكلينيكية والبيوكيميائية المصاحبة للتسمم الحاد بالمالاثيون على جهاز المناعة بمدينة المنيا ،

أحمد حفناوي عباس' و هند محمد مؤنس 2 وعمرو رضا زكي 3 ومنال عويس حسن ونجلاء علدى عبدالعظيم4

تسببت المبيدات الحشرية في زيادة انتشار الأمراض المرتبطة بالتعديلات في الاستجابة المناعية.تهدف هذه الدراسةلتوضيح بعض التأثيرات

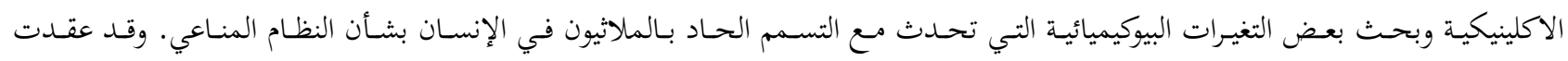

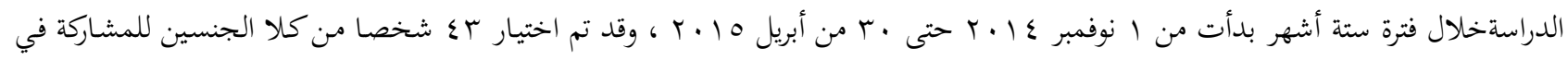

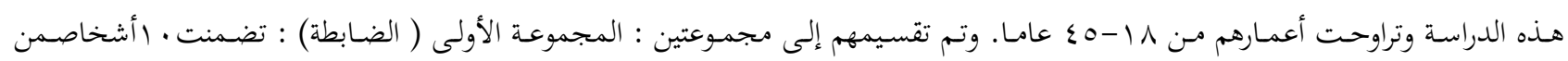

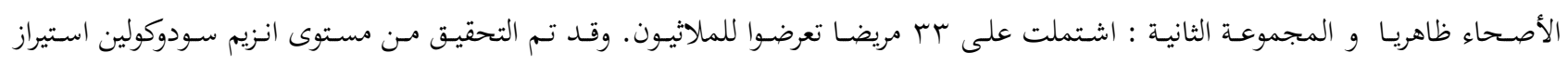

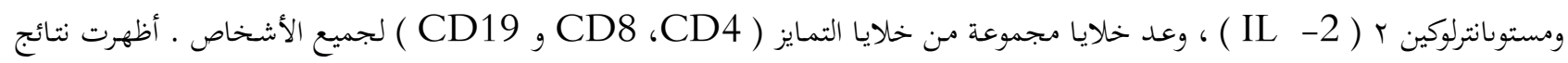

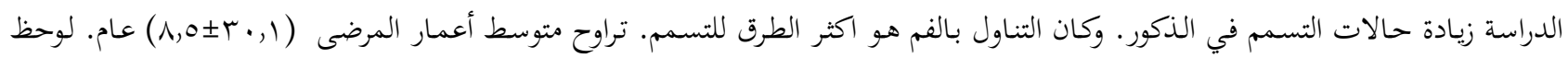

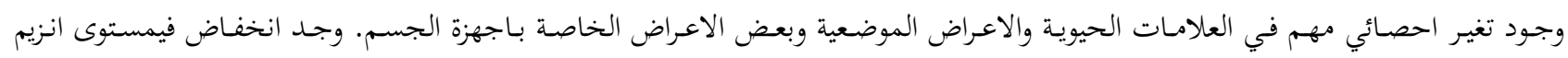

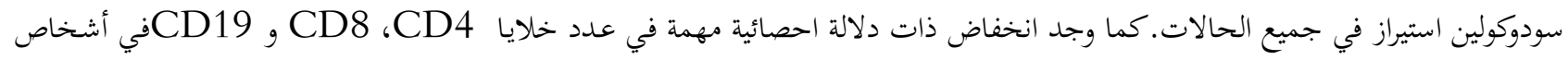

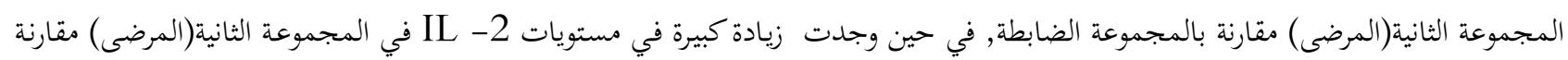

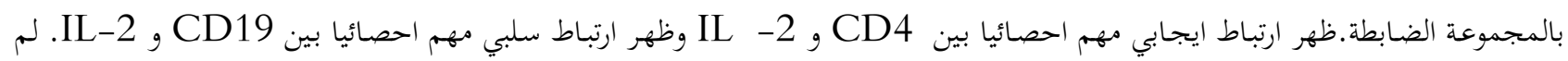

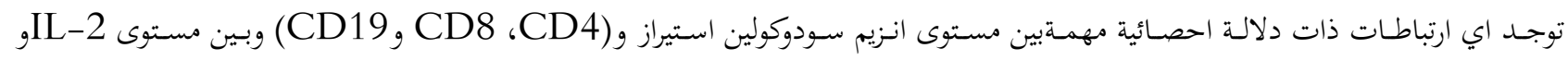

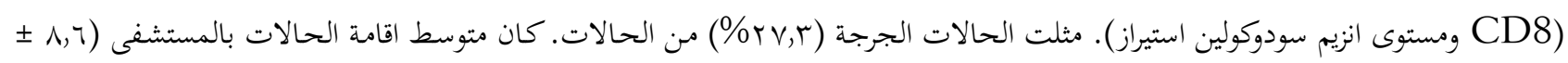

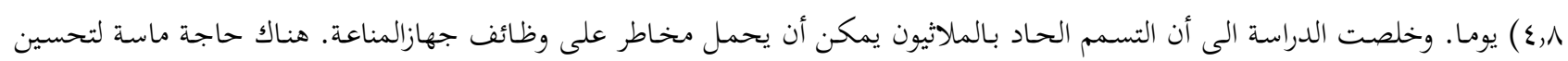

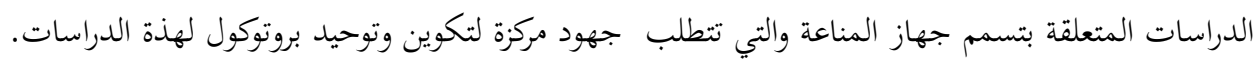

ا قسم الطب الثرعي و السموم الاكلينيكية ـ كلية الطب ـ جامعة المنيا ـ المنيا- مصر

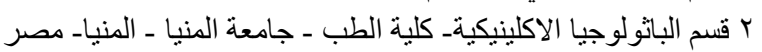

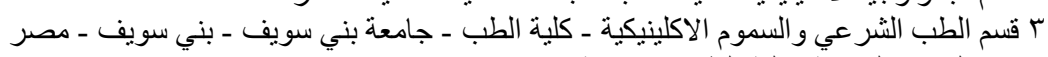

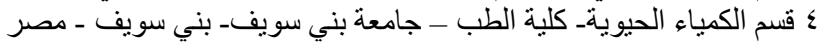

